\title{
MEMBANGUN KESADARAN BERAWAL DARI PEMAHAMAN; \\ RELASI PEMAHAMAN SEJARAH DENGAN KESADARAN SEJARAH MAHASISWA PROGRAM STUDI PENDIDIKAN SEJARAH FKIP UNIVERSITAS MUHAMMADIYAH METRO
}

\author{
Kian Amboro \\ Program Studi Pendidikan Sejarah, FKIP Universitas Muhammadiyah Metro \\ kianamboro@yahoo.co.id
}

\begin{abstract}
Abstrak
Penelitian ini bertujuan untuk menganalisis hubungan antara pemahaman sejarah dengan kesadaran sejarah mahasiswa. Jenis penelitian ini adalah penelitian expostfacto dengan desain penelitian korelasional. Populasi dalam penelitian ini adalah seluruh mahasiswa Program Studi Pendidikan Sejarah, FKIP Universitas Muhammadiyah Metro. Pengambilan sampel penelitian menggunakan teknik disproportionate random sampling. Instrumen yang digunakan untuk mengumpulkan data adalah tes pemahaman sejarah dan angket sikap kesadaran sejarah. Teknik analisis data dilakukan dengan analisis hubungan/korelasi, dan regresi linier sederhana dengan tingkat signifikansi $5 \%$. Hasil penelitian menunjukkan terdapat hubungan positif yang signifikan antara variabel pemahaman sejarah dengan kesadaran sejarah mahasiswa.
\end{abstract}

Kata kunci: pemahaman, sejarah, kesadaran sejarah.

\begin{abstract}
This research aimed to analyze the relationship between students history mastery and historical conciousness. This study was an ex-postfacto research with correlational research design. The population of research was all students of History Education Study Program of Teacher Training and Education Faculty of Metro Muhammadiyah University. The sample was taken using disproportionate stratified random sampling. The instruments used to collect the data were test and questionnare. Techniques of analyzing data used were correlation analysis, simple regressions at significance level of $5 \%$. The result of research showed that the hypotheses there are was a positive significant relationship between students history mastery and historical consciousness.

Keywords: mastery, history, historical consciousness.
\end{abstract}

\section{PENDAHULUAN}

Perkembangan kemajuan zaman dalam perjalanan panjang sejarah umat manusia adalah proses yang tidak mungkin dihindari oleh manusia sebagai makhluk yang dinamis, baik yang bersifat lokal maupun global. Bahkan perkembangan dan perubahan dalam skala gobal itu, kini masih berlangsung.

Hal itu ditandai dengan semakin memudarnya batas-batas kewilayahan dan makna spasial/keruangan. Fenomena globalisasi yang terjadi adalah faktor dari kemajuan teknologi komunikasi dan informasi yang hebat, yang kemudian semakin memudarkan batas-batas lingkungan kehidupan manusia, mungkin sebagaimana yang diungkapkan oleh Kenichi Ohmae (2002:19) bahwa batasbatas negara bangsa kini telah berakhir, sehingga kemudian muncul istilah global village yang merefleksikan suasana perapatan batasan ruang dan waktu.

Kondisi globalisasi yang tentunya memberikan kemudahan berbagai akses kehidupan manusia, ternyata di sisi lain membawa dampak yang kontras dengan itu. Globalisasi yang semakin memudarkan batasan ruang dan waktu, tentu juga akan memudarkan batas-batas kebudayaan 
sebagai identitas dan jati diri sebuah bangsa. Dalam proses globalisasi (Widja, 2002:12) bersamanya terbawa berbagai informasi yang tidak tersaring bagi generasi penerus bangsa, dan berimplikasi berbagai transmisi nilai ikut terpolusi atau terbelokkan oleh berbagai kepentingan yang tak sejalan dengan karakter bangsa tersebut.

Globalisasi tanpa disadari akan melahirkan proses homogenisasi budaya manusia. Penyeragaman budaya ini pada akhirnya akan semakin menggeser identitas-identitas setiap bangsa yang bersifat khas dan unik. Memudarnya identitas bangsa yang khas dan unik tadi sama halnya dengan mulai terancamnya keberadaan jati diri sebuah bangsa.

Kondisi ini pula yang kini terjadi pada bangsa Indonesia, masyarakat Indonesia mulai terbawa arus deras globalisasi dan tak terasa identitas dan jati diri bangsa mulai terdegradasi. Salah satu indikatornya adalah bangsa Indonesia seakan-akan mulai melupakan masa lalunya yang menjadi identitas khas setiap bangsa, karena tidak ada satu pun bangsa di dunia yang memiliki masa lalu yang sama.

Namun permasalahannya kini adalah mau atau tidaknya manusia untuk belajar dari masa lalu atau sejarahnya. Gejala masih rendahnya kesadaran bangsa Indonesia akan sejarahnya, diungkapkan juga oleh Adriaan van Dis (dalam Harian Belanda NRC Handelsblad, 9 Januari 2012) yang mengungkapkan bahwa:
"Orang Indonesia pada umumnya tidak meminati sejarah negara sendiri, mereka lebih suka mitos dan fantasi nasionalisme," demikian sastrawan Belanda Adriaan van Dis. "Memang tidak enak mengatakan itu, tapi kadar intelektual para cendekiawan Indonesia sangat kurang," tutur van Dis yang sedang merampungkan dokumenter tentang Indonesia untuk televisi Belanda.

Untuk menjelaskan gejala masih rendahnya kesadaran sejarah bangsa Indonesia, dapat merujuk pada penjelaskan Latief (2006:50) bahwa dalam kehidupan dewasa ini pola kehidupan semakin terlihat mengarah pada pola kehidupan pragmatis yang membawa kecenderungan untuk menempatkan nilai guna (terutama praktis dan materialis) saja dalam setiap pemikiran dan tindakan.

Secara eksplisit mungkin dapat digugat, sebenarnya apa yang menjadi kegunaan dan keuntungan praktis dari kesadaran sejarah. Pertanyaan ini tentu tidak salah, akan tetapi kemudian dapat dijawab bahwa memang benar kesadaran sejarah tidak menjanjikan dan tidak akan memberikan keuntungan secara praktis dan material bagi manusia. Namun harus disadari pula bahwa bukan berarti sejarah tidak memiliki nilai guna. Sejarah sebagai pengalaman tentunya dapat memberi semangat bagi kehidupan berbangsa di masa sekarang dan masa mendatang.

Dari uraian tersebut maka dapat diambil benang merah bahwa dalam kondisi saat ini kesadaran sejarah sangat relevan dan diperlukan untuk mempertahankan identitas kebangsaan di tengah mulai mengglobalnya budaya 
dunia. Hal tersebut sebagaimana yang dikemukakan oleh J. Boorstin (dalam Widja, 2002:44-45) bahwa "justru dalam masyarakat yang semakin didominasi oleh teknologi, semakin diperlukan kesadaran sejarah itu. Inti dari sejarah adalah perspektif waktu dan kontinuitas kebudayaan." Ditambahkan pula oleh Latief (2006:51) bahwa kesadaran sejarah akan mampu mengimbangi laju perkembangan ilmu pengetahuan dan teknologi yang sering terkesan melesat secara liar, sehingga pembangunan tidak semata-mata harus selalu bermuatan material akan tetapi perlu keseimbangan spritual. Kesadaran sejarah kemudian berperan dalam memperkokoh muatan moral pembangunan suatu bangsa.

Selanjutnya, kesadaran sejarah yang merupakan kebutuhan mendesak bagi bangsa Indonesia dalam pembinaannya tidak dapat dilepaskan dari pemahaman akan sejarah bangsa Indonesia itu sendiri. Melalui pemahaman sejarah maka akan muncul bentuk penyadaran bahwa sejarahlah yang membentuk kehidupan di masa sekarang serta turut menentukan kehidupan yang akan datang. Sebagaimana yang diungkapkan Anhar Gonggong dan Ismail (dalam Latief, 2006:49) yaitu sebagai berikut :

Ini perlu digarisbawahi lebih awal, sebab dalam beberapa hal pengertian tentang kesadaran sejarah bertaut erat dengan peristiwa sejarah, fakta sejarah. Hal ini tampak pula dalam pandangan Ismail yang berpendapat bahwa, "Kesadaran sejarah memang harus dimulai dengan mengetahui fakta-fakta sejarah.
Malahan adakalanya harus pula pandai menghafalkan kronologi tahun-tahun kejadian dalam sejarah itu, plus pengetahuan tentang sebab musababnya antara fakta-fakta itu."

Dalam hal ini pemahaman fakta sejarah memang bukanlah satu-satunya alat ukur penentu terhadap kesadaran sejarah. Tetapi dapat dimengerti bila tanpa adanya pengetahuan tentang sejarah sama sekali, maka kecil kemungkinan untuk dapat tumbuh suatu sikap kesadaran sejarah. Munculnya sikap dalam diri seseorang dipengaruhi oleh pengetahuannya terhadap stimulus dan pengetahuannya terhadap sikap yang akan diambilnya.

Melalui penelitian ini akan dikaji hubungan antara pemahaman sejarah dengan kesadaran sejarah mahasiswa.

\section{METODE PENELITIAN}

Penelitian ini dilaksanakan di Program Studi Pendidikan Sejarah, FKIP Universitas Muhammadiyah Metro, Lampung. Penelitian ini termasuk ke dalam penelitian ex-postfacto. Metode expostfacto digunakan dalam penelitian dimana variabel-variabel bebas telah terjadi ketika peneliti mulai dengan pengamatan variabel terikat (Kerlinger dalam Sukardi, 2005:165), dan kondisi dimana peneliti tidak melakukan manipulasi atau pengontrolan terhadap variabel bebas sebagaimana dalam penelitian eksperimen. 
Desain penelitian yang digunakan adalah desain penelitian korelasional, yang bertujuan untuk mendeteksi sejauh mana hubungan antar variabel dalam subjek atau objek yang menjadi perhatian peneliti (Sukardi, 2005:166). Data yang dikumpulkan terdiri dari dua variabel, yaitu pemahaman sejarah (variabel bebas, $X)$ dan kesadaran sejarah (variabel terikat, $Y)$. instrumen angket digunakan untuk mengungkapkan data tentang sikap kesadaran sejarah mahasiswa, yang sebelumnya kedua instrumen tersebut telah melalui uji validitas dan reliabilitas instrumen.

Setelah data diperoleh melalui instrumen, data kemudian dianalisis melalui dua langkah pokok, yaitu Uji Prasyarat Analisis dan Uji Hipotesis. Hasil

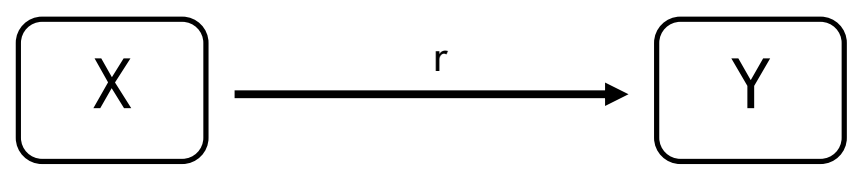

Gambar 1. Desain Penelitian Korelasi (Sugiyono, 2012:42)

Populasi dalam penelitian ini adalah seluruh mahasiswa Program Studi Pendidikan Sejarah, FKIP Universitas Muhammadiyah Metro. Pengambilan sampel dilakukan dengan teknik disproportionate stratified random sampling, yaitu sampel diambil dari populasi yang terlebih dahulu dikelompokkan dalam sub-populasi.

\section{Pengumpulan data dilakukan} dengan instrumen tes dan angket. Instrumen tes digunakan untuk mengumpulkan data yang berkait dengan data pemahaman sejarah, sedangkan dari Uji Prasyarat Analisis menunjukkan bahwa data yang diperoleh telah memenuhi persyaratan untuk dianalisis menggunakan statistik deskriptif dan parametris dalam rangkaian uji hipotesis. Pengujian hipotesis menggunakan analisis regresi sederhana. Hasil penghitungan yang akan dianalisis adalah koefisien regresi yang menghasilkan garis regresi.

\section{HASIL DAN PEMBAHASAN}

Berikut disajikan deskripsi data variabel dalam tabel rangkuman statistik deskriptif berikut ini:

Tabel 1. Deskripsi Data Variabel Pemahaman Sejarah $(X)$ dan Kesadaran Sejarah $(Y)$

\begin{tabular}{c|c|c|c|c|c|c|c}
\cline { 1 - 5 } Statistik & Mean & Median & Modus & $\begin{array}{c}\text { Standar } \\
\text { Deviasi }\end{array}$ & $\begin{array}{c}\text { Standar } \\
\text { Error (SE) }\end{array}$ & Minimum & Maximum \\
\cline { 1 - 6 }$(X)$ & 17,69 & 18 & 19 & 4,665 & 0,361 & 5 & 28 \\
\hline$(Y)$ & 122,11 & 121 & 122 & 11,143 & 0,862 & 96 & 151 \\
\hline
\end{tabular}




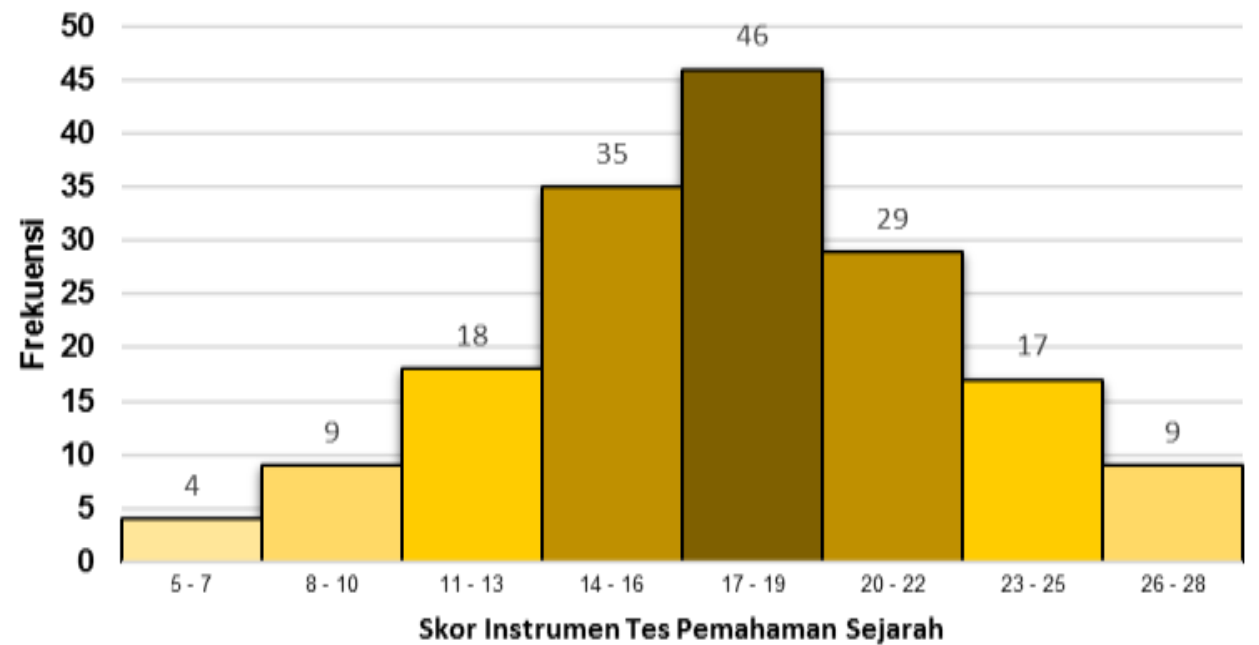

Gambar 2. Histogram Data Pemahaman Sejarah



Gambar 3. Histogram Data Kesadaran Sejarah

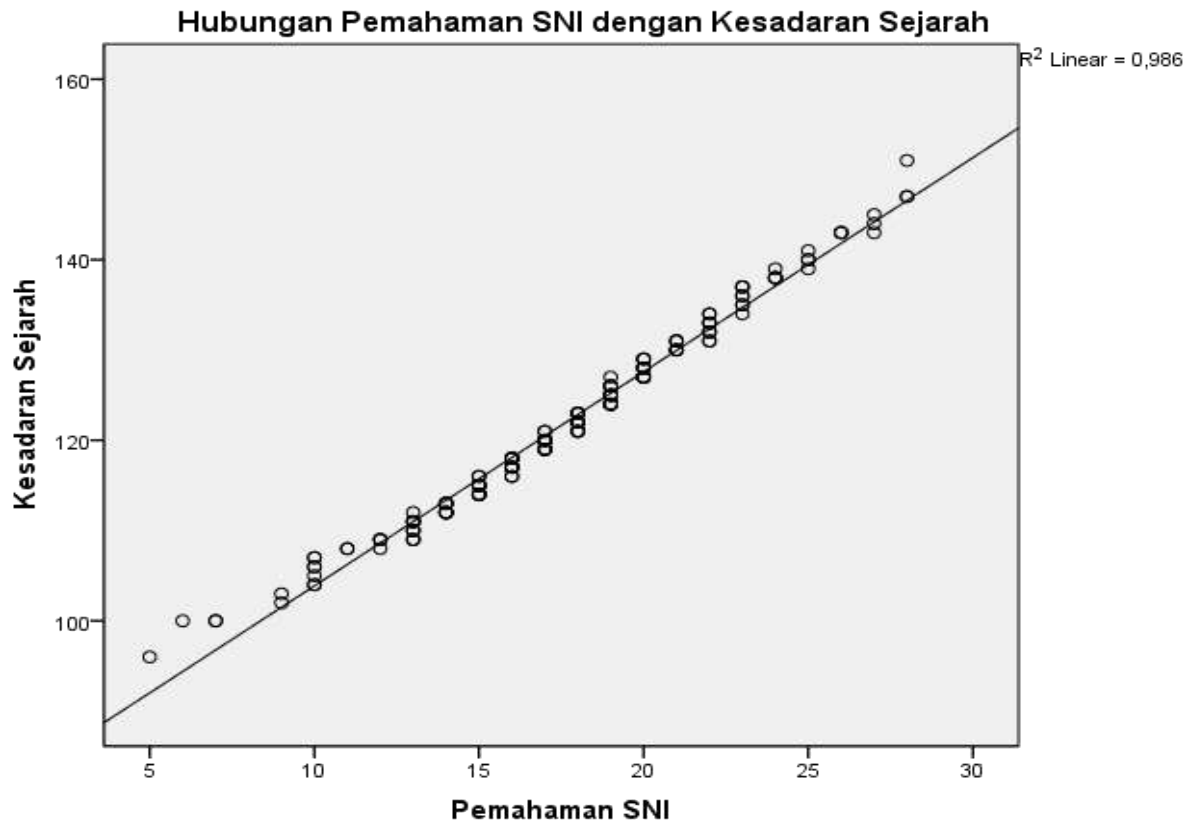

Gambar 4. Garis persamaan regresi $\hat{Y}=80,158+2,372 X$ 
Tabel 2. Rangkuman Hasil Uji Hipotesis $(\alpha=0.05)$

\begin{tabular}{c|c|c|c|c}
\hline Uji Hipotesis & Regresi & Korelasi & Uji t / Uji F & Determinasi \\
\hline$\left(X^{*} Y\right)$ & $\hat{Y}=80,158+2,372 X$ & 0,993 & $\begin{array}{c}t_{\text {hitung }}(106,367)> \\
t_{\text {tabel }}(1,654)\end{array}$ & 0,986 \\
\hline
\end{tabular}

Berdasarkan hasil penghitungan analisis data diperoleh nilai koefisien korelasi antara variabel $X$, yaitu pemahaman sejarah dengan variabel $Y$ yaitu kesadaran sejarah sebesar 0,993. Koefisien korelasi yang positif ini dapat dimaknai bahwa terdapat hubungan positif di antara kedua variabel. Peningkatan pada variabel $X$ yaitu pemahaman sejarah cenderung akan diikuti dengan meningkatnya variabel $Y$ yaitu kesadaran sejarah.

Hal ini semakin diperjelas oleh hasil analisis regresi yang diperoleh arah regresi b sebesar 2,372 dan konstanta a sebesar 80,158 . Sehingga peningkatan satu unit pada variabel pemahaman sejarah maka variabel kesadaran sejarah akan mengalami peningkatan sebesar 2,372 pada konstanta 80,158. Hasil analisis regresi ini kemudian dinyatakan dalam persamaan garis regresi $\hat{Y}=80,158+$ 2,372X.

Hasil uji keberartian koefisien korelasi antara variabel pemahaman sejarah $(X)$ dengan kesadaran sejarah $(Y)$ diketahui nilai koefisien korelasi signifikan $\left.t_{\text {hitung }} 106,367>t_{\text {tabel }} 1,654\right)$. Dengan demikian dapat disimpulkan bahwa nilai koefisien korelasi $(r=0,993)$ dapat digunakan untuk menggeneralisasi populasi variabel pemahaman sejarah dengan kesadaran sejarah. Sedangkan berdasarkan hasil analisis diperoleh juga nilai koefisien determinasi yang dalam hal ini menjelaskan seberapa besar kontribusi variabel Pemahaman Sejarah $(X)$ dalam mempengaruhi variabel kesadaran sejarah ( $Y$ ) yaitu $r_{y 1}^{2}=(0,993)^{2}=0,986$ atau $98,6 \%$. Nilai koefisien determinasi ini mengandung arti bahwa dari 100\% variabel kesadaran sejarah $(Y)$ dapat dijelaskan oleh variabel pemahaman sejarah $(X)$ adalah sebesar 98,6\%. Nilai koefisien determinasi $\left(r^{2}\right)$ juga mengungkapkan bahwa persentase sisanya sebesar 1,4\% variabel kesadaran sejarah $(Y)$ dipengaruhi oleh variabel lain yang tidak diteliti.

Berdasarkan penafsiran hasil analisis data, maka dapat kembali dijelaskan bahwa variabel pemahaman (kognitif) memiliki hubungan yang positif dan signifikan dengan variabel kesadaran (afektif). Terkait dengan pemahaman dan kesadaran, Freire

(2007:111) mengemukakan bahwa pendidikan atau proses pembelajaran pada hakikatnya bertujuan pada pencapaian sebuah kesadaran, yang oleh Freire disebut 
dengan istilah "konsientisasi” (conscientization) yang berarti penyadaran secara kritis akan kenyataan yang ada. Konsientisasi terjadi dan dibangun secara simultan melalui sebuah proses pembelajaran. Keterkaitan dengan sejarah ialah bahwa dalam konsientisasi ini terkandung sebuah refleksi, sehingga proses berjalan terus menerus seiring proses belajar secara berkesinambungan dan berkelanjutan. Karena pada hakikatnya manusia adalah makhluk sejarah, kebelumsempurnaan dan kesadaran akan ketidaksempurnaannya itulah yang menyebabkan proses refleksi akan terus berlangsung.

Ditambahkan oleh Freire bahwa hanya mentalitas mekanistik saja yang beranggapan bahwa proses itu dapat berhenti (Freire, 2007:151-159). Pandangan yang terakhir ini yang menurut Freire pada akhirnya akan melahirkan fenomena defleksi dan dehumanisasi (Smith, 2008:108).

Pemahaman akan sebuah sejarah, dengan kesadaran akan sejarah (historical conciousness) memiliki keterkaitan yang sangat erat. Sebagaimana pendapat yang dikemukakan Hariyono (1995 : 36-37) bahwa antara kesadaran sejarah dengan wawasan sejarah tidak dapat dilepaskan satu sama lain. Wawasan sejarah lebih merujuk pada aspek kognitif, sedangkan kesadaran sejarah lebih kepada aspek afeksi dan sosial. Keduanya dapat dibedakan namun tidak dapat dipisahkan. Hal yang sama diungkapkan oleh Aman
(2011:31) yaitu pembelajaran sejarah berfungsi sosiokultural, membangkitkan kesadaran historis.

Secara umum memahami sejarah bangsa Indonesia merupakan proses kognisi untuk mengetahui pengalaman kolektif bangsa Indonesia dan mengambil makna dari masa lampau bangsa Indonesia tersebut untuk dijadikan pegangan hidup berdasarkan cara pandang bangsa Indonesia sendiri, dari proses itulah maka sebuah kesadaran akan pentingnya pembelajaran dari masa lampau akan menjadi bagian yang tidak bisa dipisahkan dari sebuah kehidupan.

Kesadaran sejarah sebagai salah satu tujuan dari pendidikan sejarah adalah sikap yang perlu ada dalam setiap diri manusia yang utuh, utuh akal pikirnya, serta utuh jiwa dan rasanya. Oleh karena itu dalam masyarakat yang memiliki kesadaran sejarah sebuah dehumanisasi tidak akan pernah terjadi. Pemahaman pada sejarah akan membuat manusia menjadi mengerti mana yang perlu dilakukan dan mana yang tidak, serta apa perlu dipertimbangkan dan mana yang sudah semestinya.

\section{PENUTUP}

\section{Simpulan}

Berdasarkan hasil analisis data dan pembahasan, maka dapat disimpulkan bahwa terdapat hubungan yang positif dan signifikan antara variabel pemahaman sejarah dengan kesadaran sejarah. Meningkatnya variabel pemahaman 
sejarah cenderung akan diikuti oleh peningkatan variabel kesadaran sejarah.

Diperoleh juga kesimpulan bahwa variabel pemahaman sejarah memberikan sumbangan sebesar 98,6\% dalam 100\% variabel kesadaran sejarah, dan 1,4\% sisanya dipengaruhi oleh variabel lain. Hal ini menjelaskan bahwa dalam menumbuhkan dan membangun kesadaran sejarah, faktor pemahaman sejarah adalah sangat penting serta tidak dapat diabaikan.

\section{Saran}

Berdasarkan simpulan yang telah dikemukakan di atas, maka dapat diberikan saran antara lain:

- Kesadaran sejarah menjadi variabel penting bagi setiap bangsa. Kepada para pengambil keputusan, penentu kebijakan, dan pemangku kepentingan (stake holder) agar senantiasa menjadikan sejarah sebagai sebuah alasan pertimbangan dalam kondisi apapun. Tidak diragukan lagi bahwa sudah semestinya manusia belajar dari pengalaman, demi kehidupan yang lebih baik.

- Pemahaman sejarah dapat dijadikan prediktor dalam meningkatkan kesadaran sejarah, oleh karena itu kepada para penyelenggara pendidikan umumnya, dan pendidik sejarah khususnya, agar dalam rangkaian proses pembelajaran sejarah (perencanaan, pelaksanaan, dan evaluasi) dapat dikemas dengan sebaik-baiknya sehingga tujuan pembelajaran sejarah dapat tercapai secara optimal. Kesadaran sejarah sebagai tujuan utama dalam pembelajaran sejarah hanya dapat terwujud jika pembelajaran sejarah benar-benar berjalan dengan baik.

- Kepada para peneliti, hasil kajian ini dapat dijadikan pijakan dalam melakukan penelitian lebih lanjut untuk permasalahan serupa. Sehingga kemungkinan lahirnya teori-teori baru atau memperkuat teori-teori yang sudah ada dapat memperkaya khasanah keilmuan dalam rangka pemecahan masalah kehidupan.

\section{DAFTAR PUSTAKA}

Aman. 2011. Model Evaluasi Pembelajaran Sejarah. Yogyakarta : Penerbit Ombak.

Freire, Paulo. Tanpa Tahun. Politik Pendidikan Kebudayaan, Kekuasaan dan Pembebasan. Terjemahan oleh Agung Prihantoro dan Fuad A.F. 2007. Yogyakarta : Pustaka Pelajar.

Hariyono. 1995. Mempelajari Sejarah Secara Efektif. Jakarta : Pustaka Jaya.

Latief, Juraid Abddul. 2006. Manusia, Filsafat, dan Sejarah. Jakarta : Bumi Aksara.

Ohmae, Kenichi. 2002. Hancurnya Negara Bangsa; Bangkitnya Negara Kawasan dan Geliat Ekonomi Regional di Dunia Tak Terbatas. Yogyakarta : Qalam.

Smith, William. 1987. Conscientizacao; Tujuan Pendidikan Paulo Freire. Terjemahan oleh Agung Prihantoro. 2008. Yogyakarta : Pustaka Pelajar.

Sugiyono. 2012. Metode Penelitian Pendidikan. Bandung: Alfabeta. 
Sukardi. 2011. Metodologi Penelitian Pendidikan; Kompetensi dan Praktiknya. Jakarta : Bumi Aksara.

van Dis, Adriaan. 2012. Orang Indonesia Buta Sejarah. Radio Nederland Wereldomroep Indonesia. 9 Januari 2012. Diakses 31 Maret 2013 pukul 06.29 .

Widja, I Gde. 2002. Menuju Wajah Baru Pendidikan Sejarah. Yogyakarta : Lappera Pustaka Utama. 
Membangun Kesadaran berawal dari Pemahaman..., Kian Amboro, 109-117 